\title{
Designing an Information System for Updating Land Records in Bangladesh: Action Design Ethnographic Research (ADER)
}

\author{
Laurence Brooks and M. Shahanoor Alam \\ Department of Information Systems and Computing, Brunel University, UK \\ \{Laurence.Brooks, Muhammad.Alam\} @brunel.ac.uk
}

\begin{abstract}
Information Systems (IS) has become a research discipline accommodating and adapting diverse methodologies, methods, and techniques from reference disciplines as well as generating them. Action Design Research (ADR) has been developed as a broad research method, based on empirical study within developed countries. However, there remains a lack of methodologies for studying IS in the complex context of developing counties. This pioneering application of ADR in a developing country context identified that ADR requires additional lenses for understanding this additional complexity. Further, combining ADR with an ethnographic methodological framework has potential complementarity within IS research. This helps the researchers cycle through the problem formulation, design, evaluation, reflection and learning cycles. This paper therefore argues that Action Design Ethnographic Research (ADER) is a potential methodological framework for IS research. While developed from a specific case of land records service in Bangladesh, ADER shows potential as a rigorous methodology for conducting IS research in any complex context.
\end{abstract}

Keywords: Action Design Research, Action Design Ethnographic Research, Land Records Management, Bangladesh.

\section{Introduction}

Information Systems (IS) research already draws methodological and theoretical contributions from many reference disciplines (Thompson, 2012). Anthropology is one of these valuable reference disciplines and ethnography, as a subfield of anthropology which has potential contributions in qualitative studies in IS (Nandhakumar and Jones, 1997; Myers 1999). Ethnography refers to a paradigm, a methodology and a basket of tools and techniques (Geertz, 1973; Westbrook, 2008). As a research methodology, it has been used in IS research for over the last 20 years and played a substantial role in theory building (Walsham, 1995; Orlikowski, 1992). The nature of ethnographic research is empirical, longitudinal, inductive, long term, participant observation oriented and interventional. Thus ethnographic research is helpful for theory building (Orlikowski, 1992; Orlikowski and Gash, 1992; Walsham and Sahay, 1999). Ethnographic research provides a unique opportunity for insight into everyday 
practices through applying the dual perspective of the emic view (insider) and etic view (outsider) (Geertz, 1983). It provides insights into IS research (Walsham 1995) and shows complementarity with applied and interpretive research e.g., action research (Nilsson, 2000), design research (Barab et. al., 2004). This paper aims to explore how an ethnographic methodological perspective contributes to Action Design Research (ADR) (Sein et. al., 2011), a newly developed research method in IS.

The main objective of this paper is to seek a broader methodological framework for understanding complex organizational contexts, everyday organizing, practices, informal organizational behavior and networks and dichotomy in organizational processes. These features are commonly visible in IS research in developing countries. This paper shows that ADR is a potential research method for understanding IS in the complex context of developing countries, whereby an ethnographic methodological framework has potential complementarity for conducting ADR. The findings are derived from a longitudinal empirical study in a public sector organization in Bangladesh, in which an ethnographic methodological framework and ADR has been applied, as Action Design Ethnographic Research (ADER). A recent study has demonstrated how ethnographic perspectives, approaches and tools are potentially very useful for conducting ADR in these complex developing countries contexts (Alam et. al., 2012).

\section{Action Design Ethnographic Research}

Action Design Research (ADR) aims to build ensemble artifacts in organizational contexts to generate prescriptive design knowledge through building and evaluating ensemble IT artifacts in organizational settings (Sein et. al., 2011; Hevner et. al. 2004). ADR thus harnesses complementarity between Action Research (AR) and Design Research (DR) to build a rigorous methodology for studying these artifacts. Hence, ADR aims to build artifacts in organizational contexts through framing DR into AR cycles. Similarly, Gregor and Jones (2007) show that designing an ensemble artifact requires interactions between technological and organizational dimensions while organizational contexts, structures and networks play significant roles. Ensemble IT artifacts emerge from design, use, practice and on-going refinement in organizational contexts.

However understanding organizational context and building artifacts in organizational context are highly challenging because organizational context refers to the complex fabric of local culture, people, resources, purposes, earlier events and future expectations that are bounded by time-space-situation (Evered and Louis, 1981). Understanding the organizational context of IS research in developing countries is equally important and complicated. Therefore, in order to understand organizational context, IS research suggests applying different modes of enquiries, perspectives and roles of researcher - Barley's (1986) 'emic and etic' perspectives; Evered and Luis's (1981) 'outsider and insider mode of inquiry'; Nandhakumar and Jones' (1997) 'distance and engagement' perspectives. These perspectives, derived from an ethnographic methodological framework, are briefly discussed to understand the framing of ADR in such a framework. 


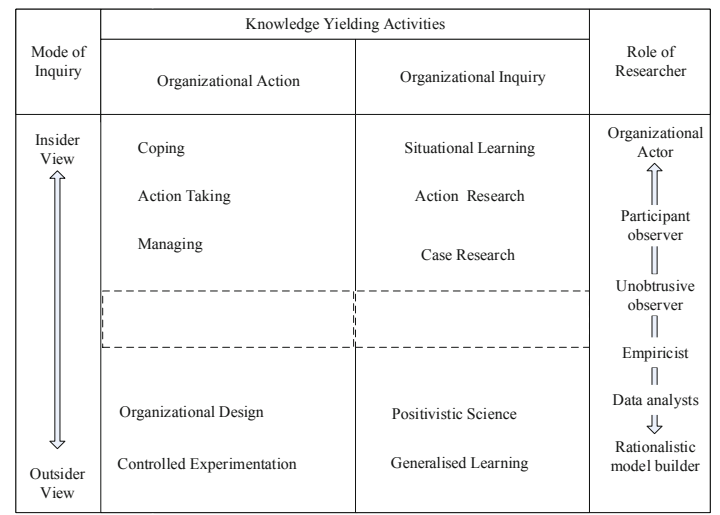

Fig. 1. Insider and Outside Modes of Inquiry (Evered and Louis, 1981)

Evered and Louis (1981) suggested applying insider and outsider views to the ethnographic perspectives, to understand organizational contexts with different roles and involvement of researchers along with methods, learning and epistemological strands (see figure 1). Both views are complementary to elicit insights of the situation under study.

The outsider view generates research findings usually with quantitative data, questionnaires and passive observation. The insider view generates data by 'being there' and becoming immersed in the organizational activities through participant observation and playing the role of organizational actor. Further, there is the opportunity to examine one situation from different lenses and stances. So, it is possible to derive situational learning and generalized learning. Thus applying both perspectives enhances the validity of analyses and interpretations by bringing the world of interpretations and the world of scientific theory together (Schutz, 1973). Ethnographic perspectives, therefore, have the potential for understanding organizational contexts with various roles, modes of inquiry, actions from various dimensions and generating both situational and generalized learning.

Nandhakumar and Jones (1997) emphasize the ethnographic perspective along with participant observation and argue that though researchers enter into the actors' world, there are a number obstacles, including deceptive behavior, sensitivity, deliberately misleading, dominant perception, actors' inability of expression, to understand their interpretations (Nandhakumar and Jones, 1997). Researchers, therefore, need to observe actors' response, note their gesture and watch bodily responses to what's going around them with an engagement (Goffman, 1990).

Finally, Barley (1986) applied both insider view (emic) and outsider view (etic); the insider view elicits context, practices and way of life from the perspective of participants along with concepts of the native's worldview; the outsider view relies heavily on the perspective of the researcher, uses the concepts of social science and aims to analyse the context, practices and ways of life theoretically (Barley, 1986). Applying both perspectives gives rich insights but it is difficult to apply them. Barley (1986) suggests two ways: a) taking a collaborating role and b) a commitment to long term involvement. 


\section{Action Design Ethnographic Research Framework (ADER)}

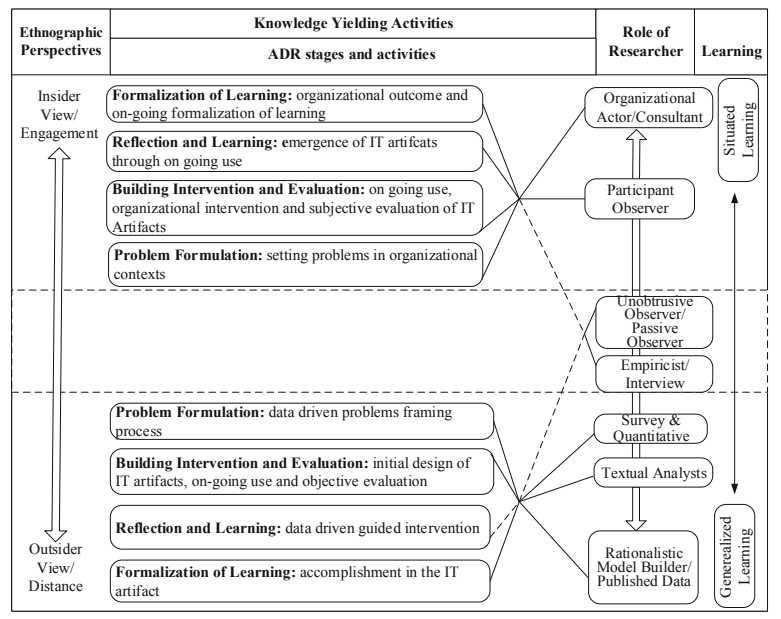

Fig. 2. Ethnographic Perspectives in ADR Process

ADR aims to build artifacts in organizational contexts and to refine them through ongoing use, intervention and evaluation in organizational contexts whereby the ethnographic perspective(s) is a potential lens for understanding it. Thus it can be seen that an ethnographic methodological framework has complementarity with all the stages and activities of ADR (see figure 2). Formulating problems in organizational contexts entails a mutually influential and reciprocal role in shaping artifacts, objective evaluation, emergence of artifacts and learning as organizational actors are significantly relied on to provide understanding from an insider perspective. On the contrary, data driven problems formulation, initial design, on-going evaluation, guided intervention and learning as researcher all come from an outsider perspective. Therefore the ethnographic perspective in ADER (see figure 3) allows for better integration of the inside/outside perspective than traditional ADR alone and can be seen as an extended variant of ADR.

\subsection{Problem Formulation}

ADR formulates problems in organizational contexts drawing from empirical evidence and data driven by end-users and existing technologies (Sein et. al., 2011). Researchers' engagement, long term involvement, observation, participant observation and being an actor in the context bring a type of empirical evidence derived from applying the insider view which discovers underlying meanings of organizational contexts that are expressed through actions and artifacts (Prasad, 1997). The outsider view applies 'looking on' in the sense of witnessing and examining processes and contexts externally to produce logical meaning and measurement (Evered and Louis, 1981). Consequently, this view allows the researcher to frame data driven problems. ADR also formulates data driven problems because it follows a cyclical process between problems formulation to evaluation stages 
ie. problem, fix, problem, fix, as if in a 'systems development life-cycle' (see figure 3) (Sein et. al., 2011; Mantei and Teorey, 1989).

\subsection{Building Intervention and Evaluation (BIE)}

This stage iteratively interweaves between three core activities i.e., building artifacts; intervening in organizational settings and evaluating concurrently and objectively (Sein et. al., 2011). BIE principles (reciprocal shaping between artifact and organizational contexts; mutual learning between researcher and practitioners; applying on-going and objective evaluation) require both insider and outsider views. These principles include observation, involvement, interpretation and intervention whereby the insider view elicits insights from them. In contrast, the outsider view is important for these BIE principles for applying the researcher's theory of knowledge according to existing technologies and resources and conducting context free objective evaluation.

Researchers' engagement as participant observation (insider view) is significant in information systems design, implementation and use because it sees nothing as surprising (Nandhakumar and Jones, 2002). It seeks meaning of every observation; what those observations mean and why (Kelly and Gibbons, 2008). Thus, applying the insider view develops meaningful interpretations from the iterative relation between organizational contexts and designed artifact.

Further, an ethnographic perspective brings forth 'live experience', including behavior, attitudes, practices, roles of actors and how they help to design change supported by local transformation (Barab et. al., 2004). Applying the insider view, therefore, enhances the mutually influential role between researcher's knowledge and the actors' practices. As Sim (1999) noted, the ethnographic perspective has the potential to design artifacts and redesign them through contextualizing organizational practices. Furthermore, the insider view provides insights from evaluation in organizational contexts (Nedevschi et. al., 2006) because it does not leave actions as: being absurd, peculiar, pointless, irrational, surprising or confusing, rather finds their existing meanings lying in the local context and culture (Lee, 1991). We refer to it as interpretive subjective evaluation; where subjective does not mean bias, rather it aims to seek contextual meanings and examine how the meanings interact with artifacts. This evaluation aims to reflect the actors view and situated learning from ADER.

On other hand, the outsider view gives an opportunity to conduct a context free and objective evaluation. Moreover, it allows researchers to filter the on-going activities as well as learning through their preset categories, codings that derive factual data and results as an objective evaluation (Evered and Louis, 1981). Although ADER is highly situated, objective evaluation seeks to generalise its outcome. Since the researchers' involvement in organizational context might hinder objective evaluation and give rise to a conflict of interests. Thus the outsider view gives objective and context free evaluation in ADR.

\subsection{Reflection and Learning}

Reflection and learning is derived from formulated problems, theoretical premises and emerged solutions that contribute towards research processes and knowledge 
(Sein et. al., 2011). It applies 'guided emergence' a principle containing two contrasting views 'guided' and 'emergence' (Sein et. al., 2011). The former refers to guided intervention i.e. an outsider's view, and the latter displays a sense of organic evolution i.e. an insider's perspective. ADR, therefore, recognizes that understanding emerging artifacts through on-going use requires both insider and outsider views (Sein et. al., 2011). It can be seen that organizational contexts, practices and users' roles reshape the initial design of artifacts whereby alone the outsider view/distance relation cannot trace the emerging shape of artifacts because it requires close observation and engagement. However it requires guided intervention with logic, model and theory to redesign the emerged artifacts. Thus, both perspectives enhance the reflection and learning process of ADR.

\subsection{Formalization of Learning}

This stage aims to formalize learning through generalizing the 'situated learning' (van Aken, 2004). The situated nature of ADR outcomes includes organizational change and implementation of an artefact. Researchers, therefore, need to describe organizational outcomes and outline the accomplishments in artefact formalised learning.

The ethnographic perspective in IS bridges the gap between academics and practitioners through generating valuable learning and contributing to knowledge (Myers, 1999). It provides analyses that are communicable and predictable (Sanday, 1979). Organizational outcomes can be best expressed by organizational actors and in order to identify that the researchers' engagement as an actor (insider perspective) is important. Contrary, applying the outsider view transmits situated learning into generalised learning that could be applicable to other similar contexts (Evered and Louis, 1981). The outsider view helps to build a rationalistic model to transmit the situational learning into generalized design principles, and outline the accomplishment in the artifacts from the ADR.

Therefore, the ethnographic perspective fits throughout the stages and activities of ADR with a complementarity towards the end of advancing ADR in complex contexts (see figure 3). They allow the formulation of problems and design artifacts (BIE) in multiple cycles; evaluate the on-going use of artifact from different positions and identifying and transferring learning. More importantly, applying the ethnographic perspectives iteratively in problem formulation and BIE generates significant insights and detailed findings. Thus applying ADR with an ethnographic methodological framework means it is able to draw out an ethnographic description as an outcome that can be seen as Geertz's (1973) thick description. 'Thick description' unfolds multiple layers of meaning held by the members and practices of the organization (Nilsson, 2000). Notably thick description aims to contribute to knowledge through providing detailed analysis of ADR findings. Therefore ADER is a potential methodological framework for IS studies and it is illustrated with a case of the service for updating land records in Bangladesh. 


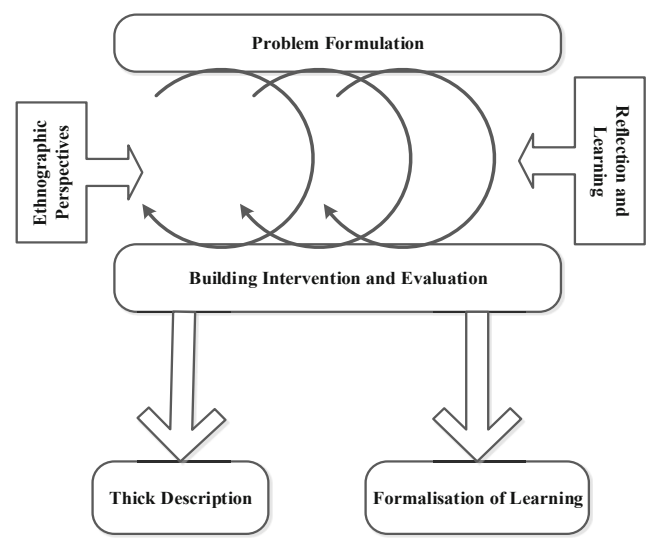

Fig. 3. Action Design Ethnographic Research (Adapted from Sein et. al., 2011)

\section{Data Collection Methods}

Both ADR and ethnography seek long term involvements and commitments of researchers. With these notions, this study gathered data from longitudinal, interventional and participant observation oriented approaches and processes. The study was conducted for about $2 \frac{1}{2}$ years in a public sector organization in a sub-district of Bangladesh, called Upzila, Land Office, Rooppur (not real name). The study focused on improvements to the service involved in updating land records locally and throughout the country.

The ADER was been initiated by the Office of the Divisional Commissioner, head of the land and revenue administration divisional level. The ADER team comprises of both professional and practitioners. The lead author worked as the Section Officer in the Divisional Commissioner Office and presented the problems updating land records in several meetings, workshops and training sessions with the officers involved. In addition, the lead author took the opportunity to use participant observation arising from his responsibilities i.e., coordinating with the decision makers of this service and the decision implementers of this service.

This ADER was been initiated in October 2009 and the findings tracked until June 2012. Therefore throughout the ADER process, the findings are derived from participant observation and interventions arising from field visits, inspections, official reports and documents analyses, workshops, meetings, consultations and training exercises, policy formulation and implementation, all relating to updating land records.

The initial design process was been launched in December, 2009 in just one district. Thereafter nine districts have implemented the initial design in January, 2010. The initial design was further redesigned and that has been implemented throughout the country since April 2010. This paper now focuses on how organizational context has further redesigned the implementation process (the redesign) of the land records updating service in Bangladesh. 


\section{$5 \quad$ ADER Findings}

\section{$5.1 \quad$ Background}

Updating land records is a core service delivery for citizens in Bangladesh. It has been identified as problematic and outdated, a source of corruption and litigations by the government itself, the development partners, practitioners and civil society. Rampant corruption in this service delivery is a barrier to economic growth. In addition to fraud, forgery and physical assaults, some murders took place due to land record litigations, which are also responsible for $80 \%$ of all civil cases and $70 \%$ of all criminal cases (Barakat and Prasanta, 2004).

Bangladesh is a populous country with a total of 160 million people, while the average land per person is only 0.22 acre. However, it relies on an agro-economy because agriculture contributes $60 \%$ of total GDP. It is noteworthy that land is the only capital and source of livelihood for the majority of people. About $80 \%$ of people depend on agriculture and the rate of land ownership transfer is very high. Updating of land records is, thus, a significant service to the citizens.

Updating land records refers to updating the name of the owner of land in record registers after land registration (purchase) or inheritance (either loosing or gaining). This process is called 'mutation'; mutating records from one name to other. This service is delivered from a public sector organization namely the Upazila Land Office (ULO). Upazila refers to a sub-district, the bottom tier of public administration in the country. There are a total of 500 ULOs in the country. The ULO is headed by the Assistant Commissioner of Land (ACL). A ULO comprises of several local union Land Offices (LO) that is headed by a Union Assistant Land Officer (UALO).

There are two ways of updating land records: ULO's initiatives and citizens' application. Firstly, the ULO can update land records on the basis of two information networks: one, receiving a Land Transfer Notice after land registration is completed by the SubRegistrar Office and the other is a report from a LO. According to the government rules, following land registration a Land Transfer Notice is issued to the ULO for updating the appropriate records. On the other side, where there is the death of a land owner or any change takes place in the type of land, the LO reports to the ULO for the purpose of updating land records. However, functionally, updating land records by ULO's initiative rarely takes place. The ULO, therefore, updates land records on the basis of citizens' applications which require fees and lists of documents; land registration deeds, certified copy of original records, sketch map of the land plots, inheritance certificate from local union council. Thereafter the ULO conduct an initial scrutiny on the fees and supporting documents and ask the concerned LO for its field inspection report. The ACL calls the applicant the first party (or new owner) and the second party, the seller and related individuals, and consults the LO's report and scrutinizes the registers of the ULO. Finally, the ACL either approves the application i.e., updates the land record, or rejects the application i.e., no change in the original details.

\subsection{Problems Formulation}

Citizens' access to this service is complicated because from application submission to service delivery requires a number of documents and processes. The ULO often neither 
has application forms nor the guidelines on supporting documents and the processes that need to be followed. Therefore, in order to mediate access to this service, several vested interest networks, known as 'bribery networks', have been developed within and beyond the organization which they mediate as informal intermediaries.

\section{Data Driven Problems Formulation}

Citizens are not well acquainted with filling out the application form, the exact amount of fees, required documents and to whom and where the application should be submitted and how the service is to be delivered. Even after submission, it's common for the application to go missing or be rejected without any notification. Since access to this service requires filing applications with appropriate documents and a follow up set of processes, it is difficult for citizens to submit an application and track the processes without any actor in the vested interest networks - the middleman, the stamp vendor, lawyers, deed writers and the subordinate staff of ULO or LO.

\section{Context Driven Problems}

From the inception of this service it has been kept as a complex set of processes and used as a source of vested interests by the actors within the organization and beyond. Citizens rarely understand the process because there is no information system explaining this service. Even educated citizens enter into this service through the vested interest networks either through buying the application form, using the service to accomplish tasks within the shortest period of time or making possible an impossible or legally challenging case. The actors in the vested interest networks maintain application format, requirements and supporting documents privately and only use them in the case of their vested interests. Further, they expedite this service delivery in the cases of their clients' applications. As a result, applications with vested interests receive the fastest service delivery and all others are kept pending, sometimes for several months.

Therefore, the data driven and problem context can be summed up as the ULO does not have any information systems for citizens; for example, the application form, point of application submission, exact amount of fees, specific list of supporting documents, receipt for application submission, tracking options after submission, duration of service delivery and decision on the application. Whereas the organization failed to develop and maintain the information systems for this service, the actors of the vested interest networks have developed and maintained them. It could be seen as mutually dependent because the vested interest networks maintain the information systems for this service, but the organization is both dependent on them and do not find ways to overcome the problems of vested interests.

\subsection{Building Interventions and Evaluation}

\section{Fieldwork}

ADER aims to support the design of an IS to address the problems with and enhance citizens' access to the land records management service, to eradicate the vested interest networks. To this end, two pieces of fieldwork took place (one for $2 \frac{1}{2}$ months and one for 2 months) as well as relevant documents and reports were reviewed. 
In addition, three interactive workshops were arranged, for reciprocal consultations with the officers and staff of this service delivery. As a result, a number of components have been designed.

\section{Initial Design}

Initially, through the ADER a single application form was developed that aims to enhance citizens' access to this service through the organizational process, rather than through the vested interest networks. The newly designed application form has been kept as simple and informative as possible for citizens. Anyone with basic literacy and writing would be able to fill in the form. The application form contains the necessary information and instructions relating to this service delivery - with no fee for the application form; updating land records fee BDT 250.00; and 30 working days duration for service delivery. All this information is printed on the opposite side of the application form. The application form has been divided into two parts: the first part is filled in by the citizens and the second part is the acknowledgement of application receipt and for issuing an application ID. In addition, the date of the hearing is given on receipt of the application. Thus the initial design of the application form has tracking options. Nearly all the tracking information contains the acknowledgement receipt of the application form. This is issued to the applicant at submission by the ULO staff.

\section{On-going Use and Evaluation}

This initial design was implemented in 10 districts for about five months. During this period the ADER team closely observed and evaluated the on-going use and implementation. Since the newly designed application form is available and given freely by the ULO, it has attracted citizens to come to the ULO. Consequently, the practice of submitting and mediating citizens' applications by the actors of the vested interest networks has been significantly reduced compared to the previous system. Furthermore, observation and empirical findings showed that $1 / 3$ of the applicants' submitted applications directly to the ULO while previously it was less than $1{ }_{10}$.

However, it has not become possible to uproot the vested interest networks totally. While implementing the newly designed application form, the actors of the vested interest networks found that their application forms, the previous one, are no longer required for this service. The actors beyond the organizational process are involved in assisting in filling in the form for illiterate people, processing the supporting papers and submitting applications on behalf of their clients in the newly designed system.

Equally, the actors both within the organization and beyond reprint/copy the newly designed form for their clients. Consequently, they shift from their old version of the application form to the newly designed one. As a result, the benefits of the new system do not fully reach the citizens because it has been also partially utilized by the vested interest networks. While a significant number of citizens submit their application by themselves, applications from vested interest networks receive better and quicker service delivery than the rest. 


\section{Reflection and Learning: Emergence of Artifacts}

The on-going use of the new system reflects two aspects: one, the actors in the vested interest networks remain visible through filling in and submitting the application forms for illiterate people. Secondly they are involved in processing papers and expediting the service delivery for their clients. Since the application submission process did not exclude them from submission of applications, they continue their alternative route. Further, the long list of supporting documents means the application remains a complicated process, especially for illiterate and inexperienced citizens. Thus a section of citizens need to rely on the vested interest networks to appropriately arrange the list of supporting documents. Therefore, the initial design has been reshaped through on-going use.

\section{Redesign: Guided Intervention}

From the initial design and its on-going use, three things have emerged as artifacts that reshaped the initial design - a) submitting applications for their clients; b) assisting in filling and arranging complex set of supporting documents and c) expediting applications with the vested interests. In order to address them, guided interventions were made.

Firstly, receiving applications only from the applicant or his/her representative is one way to exclude the vested interest networks. Therefore, the application form has been redesigned so that the applicant needs to put his/her or his/her representative's photo on the application. If an applicant fails to submit his/her application, s/he could nominate a competent representative related to his family to the ULO for application submission.

Secondly, the list of supporting documents has been reduced and simplified so that citizens' do not need to rely on actors of the vested interest networks for arranging them. To this end, the supporting documents have been documents redesigned in such a way that if updating of the land record (mutation) has been done previously, then only that updated record is needed for the supporting document, nothing else. It makes it easier for citizens to process their application by themselves. Further, if there is any lack of supporting documents with applications, the applicant could submit them during the hearing. This reduces rejection of applications submitted by citizens.

Thirdly, the first come first served rule has been introduced in order to prevent the process of expediting applications by vested interests. Since every application is to be given an ID number during its submission by the ULO, this also provides the basis for a chronological order. In addition, it has been taken as policy to complete the application within 30 working days. Together, these interventions have given citizens' easy access and greater reliability.

\section{Subjective Evaluation}

However, within a year of implementation the redesigned system has also been further reshaped by the vested interest networks. Firstly although it is mandatory to submit the application with the applicant/representative photograph on the application form, it could be faked or be one of the actors from the vested interest networks. Mainly the actors from the vested interest networks from outside of the organization 
are involved in the process of fake photograph pasting on the applications that they submit. While an applicant comes into contact with actors of the vested interest networks, either it is the requirement of the applicant or it is the offer of the actor of vested interest networks to manage every process on their behalf. It provides greater profit to the actors and less hassle to the applicant for the vested interest network actors to process everything on behalf of the applicants.

In addition, the vested interest networks reshaped the chronological order of the process in order to deliver this service. Since, the application receipt register is maintained manually it is possible to tamper with application IDs and receiving dates. The application ID and date of receipt become significant because of the 'first come first served' system.

\subsection{Reflection and Learning: Emergence and Intervention}

Adding a photograph to the application aims to ensure that only the applicant could submit an application. With the help of a photograph, it should be easy to identify whether s/he is an applicant or not. However, the issue of the photograph has been kept outside the service delivery process because it does not have any other role and reflection in the record updating process.

Equally, a paper-based and manual receipt register has allowed the opportunity for tampering with the date of receipt and the chronology of application ID number. The staff have several means and techniques to do this. From observation, it appeared that while issuing an application receipt, the staff allocates the application ID number to the application but they put all the applications' ID number into the register once a week or fortnightly. This allows them to manipulate the chronological order of the service delivery.

\subsection{Formalization of Learning}

The initial design was implemented for 5 months in 10 administrative districts in Khulna division. Following the Ministry of Land engagement with this ADER project a divisional level workshop was conducted with ACLs by the researcher; this enabled the decision making officers and the Secretary of the Ministry of Land to share their ideas and learning derived from the initial design. On the basis of the initial design and reciprocal learning from the 10 districts, the redesigned process has been issued as an official circular for the whole county by the Ministry of Land. The redesigned process has been in operation since May 2010.

\section{Learning by organizational actors}

The actors in the vested interest networks belong within the organizational process and those beyond the organizational process are mutually dependent on each other in intra and inter dimensions (ULO staff with citizens; ULO-LO staff; ULO staff). So, the initial design and the redesign process have been reshaped through the intra-action within the organizational staff and mutual interaction between the organizational staff and the other actors in the vested interest networks. Incorporating the applicants photograph has played a small role in excluding the actors of the vested interest networks 
from the application submission process because the identifier, the staff of ULO and user of the fake photograph in the application and the actors of the vested interest networks have mutual vested interests. Similarly, expediting service delivery for applications having vested interests is taking place through their mutual interaction. Therefore, the actors of vested interest networks in this service shift their position according to shifting of the design and redesign of the service process.

\section{Empirical Outcomes}

The initial design and redesign process has significantly increased citizens' direct access to this service delivery. The empirical findings show that about $1 / 2$ of the total applications are now submitted by citizens to the ULO, compared with before the initial ADER redesign process. On the other hand, the redesigned process has ensured service delivery for all applications within 30 working days compared with previously where there was no time frame and consequently at least $1 / 3$ of the applications took more than 90 working days. Further the delays often took place in the cases of weaker sections of society. The redesigned process has simplified the application submission and tracking process, empowered the citizens through putting guidelines and necessary information with the application form and achieved chronological order in service delivery, to some extent.

However, the limitation of the redesigned process is that there is no scope for prioritizing service delivery. It has both advantages i.e., visibly no scope of discrimination; and disadvantages i.e., no scope to prioritize service delivery. Consequently, prioritizing service delivery has become a hidden process through vested interest networks and the citizens need to pay a significant extra amount ('bribe') for the prioritized service. Further, the centralized application submission process in the ULO and the manual receipt register still do not stop tampering with the chronological order.

\section{$7 \quad$ Future Design}

There are many socio-economic reasons behind the existence of the vested interest networks. The paper has addressed only a few, others include: low paid organizational staff; low literacy rates; complicated records; the presence of the actors in the vested interest networks outside the organization rooted in socio-political contexts and connected with organizational staff. Removing the vested interests overnight throughout the system is difficult. It requires long term strategic interventions through iterative design and redesign of this service delivery process.

The ADER generalized a list of learning points: the distance of the relationship between the service provider and the service recipients; installing technology to prevent and reduce intervention from vested interests networks in reshaping of the design process and reducing tampering in application ID as well as chronology of the service; and decentralization of the application submission process. 


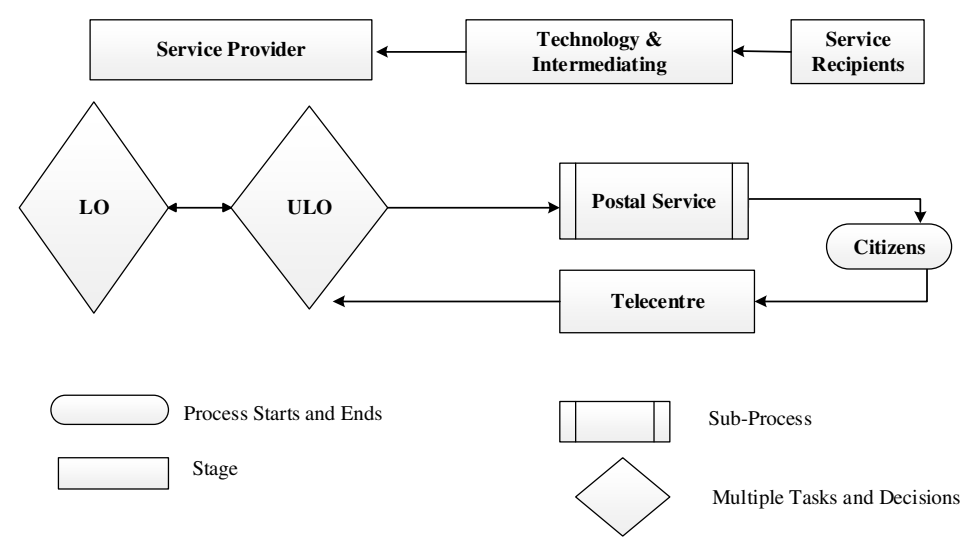

Fig. 4. Model for Further Design of Land Records Update in Bangladesh

On the basis of the generalized learning, a model (see figure 4) can be framed for further design of this service. Since the literacy rate is low, most of the citizens would require a mediator to access this service. Therefore technology mediated actors as intermediaries could help to remove the actors of the vested interest networks. They would be able to reduce citizens' interaction with service providers. Further, the country already has a network of 4501 telecentres across the rural areas. The telecentres could be technology mediated intermediaries in this service. In this way it is possible to decentralize the submission process, stop tampering and break chronological disorder. Updates could be received through SMS service or online tracking from the telecentres. Furthermore, the processed service is possible to deliver through the post, since there is countrywide public postal coverage.

The telecentres have already been mediating the service delivery of certified copies of land records to the citizens from the Deputy Commissioners office. Thus, to decentralize the application submission through the telecentres is compatible. To this end, there needs to be interfaces between the telecentres, the ULOs and the postal service developed.

Further, the Ministry of Land should revise the concept of chronological order service delivery because there should be a provision for urgent service delivery in emergency situations. In the case of urgent service, citizens are ready to pay 10-20 times higher than the usual fee to the government, which they currently pay as a bribe. Therefore, the government income would increase, the citizens would receive better service delivery and whereby incentives for the low paid service delivery staff might be possible.

\section{Conclusion}

This paper applied ADR together with an ethnographic methodological framework in order to gain a deeper understanding of the organizational contexts around updating land records in Bangladesh. It has applied an iterative process of problem formulation 
and design (BIE). ADR originally shared many of its activities and principles latently with an ethnographic perspective. Applying ADR in a developing country, it is clear that while understanding organizational contexts and building artifacts in organizational contexts remains unattainable and challenging due to the complex contexts, informal practices dominate over the organizational rules and the design processes. Thus applying ADR together with an ethnographic methodological framework helps to elicit insights into the organizational context. More importantly, an ethnographic methodological framework allows researchers to iterate throughout the ADR process. For instance, it gives an opportunity to formulate problems and interact with BIE through multiple cycles such that the context problems can be formulated from the data i.e. rather than relying on the researchers' knowledge and perceptions, the problem can be formulated through empirical evidence arising from engagement and observation. Further, understanding on-going use and redesign of artifacts is challenging in developing countries where practices are diverse, hidden and deliberately deceptive and where the researchers' engagement with the insider view is potentially very powerful. An objective evaluation is often helpful in the case of interventional research, thus applying an outsider viewpoint helps to conduct context free evaluation. However, the insider view also brings forth the researchers' reflection that could be seen as subjective evaluation. Finally, ADER has the potential to identify learning and transfer it to the practitioners through model building. Although conducting ADER is challenging because it requires long term involvement, commitment and skills, it has the potential to provide valuable ethnographic analysis i.e. 'thick description', for both IS practitioners and IS professionals.

\section{References}

Alam, M.S., Brooks, L., Khan, N.I.: Action design ethnographic research (ADER): Vested interest networks and ICT networks in service delivery of land records in Bangladesh. In: Bhattacherjee, A., Fitzgerald, B. (eds.) Shaping the Future of ICT Research. IFIP AICT, vol. 389, pp. 51-67. Springer, Heidelberg (2012)

Barab, S.A., Thomas, M.K., Dodge, T., Squire, K., Newell, M.: Critical design ethnography: Designing for change. Anthropology \& Education Quarterly 35(2), 254-268 (2004)

Barakat, A., Prasanta, K.R.: Political Economy of Land Litigation in Bangladesh: A Case of Colossal National Wastage. Nijera Kori, Dhaka (2004)

Barley, S.: Technology as an occasion for structuring: evidence from observation of CT Scanners and the social order of radiology departments. Administrative Science Quarterly 31, 78-108 (1986)

Evered, R., Louis, M.R.: Alternative Perspectives in The Organizational Sciences: Inquiry from the Inside and Inquiry from the Outside. The Academy of Management Review 6(3), 385395 (1981)

Geertz, C.: From the Native's Point of View: On the Nature of Anthropological Understanding. In: Geertz, C. (ed.) Local Knowledge, pp. 55-70 (1983)

Geertz, C.: Thick Description: Toward an Interpretive Theory of Culture. Basic Book Inc., New York (1973)

Goffman, E.: The Presentation of Self in Everyday Life. Penguin, London (1990)

Gregor, S., Jones, D.: The Anatomy of a Design Theory. Journal of the Association for Information Systems 8, 312-335 (2007) 
Hevner, A.R., March, S.T., Park, J., Ram, S.: Design Science in Information Systems Research. MIS Quarterly 28(1), 75-105 (2004)

Kelly, D., Gibbons, M.: Ethnography: The good, the bad and the ugly. Journal of Medical Marketing 8, 279-285 (2008)

Lee, A.S.: Integrating positivist and interpretive approaches to organizational research. Organization Science 2(4), 342-365 (1991)

Mantei, M.M., Teorey, T.J.: Incorporating behavioral techniques into the systems development life cycle. MIS Quarterly 13(3), 257-274 (1989)

Myers, M.D.: Investigating Information Systems with Ethnographic Research. Communications of the Association for Information Systems 2, 1-20 (1999)

Nandhakumar, J., Jones, M.: Development Gain? Participant observation in interpretive management information systems research. Qualitative Research 2, 323-341 (2002)

Nandhakumar, J., Jones, M.: Too Close for Comfort? Distance and Engagement in Interpretive Information Systems Research. Information Systems Journal 7, 109-131 (1997)

Nedevschi, S., Jaspal, S.S., Joyojeet, P., Rodrigo, F., Kentaro, T.: Bayesian networks: An exploratory tool for understanding ICT adoption. In: Information and Communication Technologies and Development, ICTD 2006, pp. 277-284 (2006)

Nilsson, M.: Organizational Development as Action Research, Ethnography, and Beyond. Paper Presented at the Annual Meeting of the American Educational Research Association (2000)

Orlikowski, W.J., Gash, D.: Changing Frames: Understanding Technological Change in Organizations. Working Paper No. 236. MIT, Sloan School of Management (1992)

Orlikowski, W.J.: The Duality of Technology: Rethinking the Concept of Technology in Organizations. Organization Science 3, 398-427 (1992)

Orlikowski, W.J.: The Sociomateriality of Organisational Life: Considering Technology in Management Research. Camb. J. Econ. 34, 125-141 (2010)

Prasad, P.: Systems of Meaning: Ethnography as a methodology for the study of information technologies. In: Lee, A., Liebenau, J., DeGross, J.I. (eds.) Information Systems and Qualitative Research: Proceedings of the IFIP TC8 WG 8.2 International Conference, pp. 101118. Chapman \& Hall, London (1997)

Sanday, P.R.: The Ethnographic Paradigm(s). Adm. Sci. Q. 24, 527-538 (1979)

Schutz, A.: Concept and theory formation in the social sciences. In: Natanson, M. (ed.) Collected Papers, pp. 48-66. Martinus Nijhoff, The Hague (1973)

Sein, M.K., Henfridsson, O., Purao, S., Rossi, M., Lindgren, R.: Action Design Research. MIS Quarterly 35, 37-56 (2011)

Sim, S.E.: Evaluating the evidence: Lessons from ethnography. In: Proceedings of the Workshop Empirical Studies of Software Maintenance, p. 66 (1999)

Thompson, M.: People, Practice, and Technology: Restoring Giddens' Broader Philosophy to the Study of Information Systems. Information and Organization 22(3), 188-207 (2012)

van Aken, J.E.: Management research based on the paradigm of the design sciences: The quest for field-tested and grounded technological rules. Journal of Management Studies 41(2), 219-246 (2004)

Walsham, G., Sahay, S.: GIS For District-Level Administration in India: Problems and Opportunities. MIS Quarterly 23, 39-65 (1999)

Walsham, G.: Interpretive Case Studies in IS Research: Nature and Method. European Journal of Information Systems 4, 74-81 (1995)

Westbrook, D.A.: Navigators of the Contemporary: Why Ethnography Matters. University of Chicago Press, Chicago (2008) 